\title{
Influence of Tunneling in Cohesionless Soil for Different Tunnel Geometry and Volume Loss under Greenfield Condition
}

\author{
Raja Kanagaraju $\mathbb{D}^{1}$ and Premalatha Krishnamurthy ${ }^{2}$ \\ ${ }^{1}$ Department of Civil Engineering, Kongu Engineering College, Perundurai, Tamilnadu 638060, India \\ ${ }^{2}$ Department of Civil Engineering, College of Engineering Guindy, Anna University, Chennai, Tamilnadu 600025, India \\ Correspondence should be addressed to Raja Kanagaraju; krajakec@gmail.com
}

Received 24 December 2019; Revised 21 April 2020; Accepted 2 May 2020; Published 19 May 2020

Academic Editor: Sanjay Nimbalkar

Copyright (c) 2020 Raja Kanagaraju and Premalatha Krishnamurthy. This is an open access article distributed under the Creative Commons Attribution License, which permits unrestricted use, distribution, and reproduction in any medium, provided the original work is properly cited.

\begin{abstract}
This paper presents the numerical analysis of settlement to profile the vulnerable zone or influence zone due to tunneling activities in cohesionless deposits for free field or Greenfield conditions. The analysis considers the factors like saturated density $\left(\gamma_{\text {sat }}\right)$, unsaturated density $\left(\gamma_{\text {unsat }}\right)$, angle of shearing resistance $(\varphi)$, deformation modulus $\left(E_{S}\right)$, volume loss $\left(V_{L}\right)$, and the support pressure of the shield head at the tunnel face. The obtained results using a finite element program (FEM) PLAXIS 3D are compared with measured and predicted surface settlement using field measuring instruments, and analytical and empirical solution show a reasonable agreement and are found to be conservative. From literature, for Greenfield condition the ground settlement equal to $10 \mathrm{~mm}$ is taken as the minimum value to map the influencing zone considering the fact that the structure which lies beyond this zone would undergo negligible settlement. Settlement trough and $10 \mathrm{~mm}$ settlement contour characteristics are presented for different tunnel sizes placed at the same depth and the same tunnel size placed at different depths, respectively. Various influencing zones are arrived for the sandy grounds of different denseness based on the parametrical studies involving parameters such as tunnel size " $D$," tunnel axis depth " $z$," and volume loss " $V_{L}$."
\end{abstract}

\section{Introduction}

Tunneling in granular soils is considered to be a sensitive case as there is a challenge for a designer to predict the ground losses and their associated settlements. In cohesive soil, there are some lines evidence [1] to suggest that the whole of the soil volume lost at the tunnel appears as a settlement depression at ground surface with noncohesive soil, which may not be so. The volume losses that occur in granular soils may not reach the surface but cause loosening at the vicinity of tunnel outer skin. Conversely, tunneling disturbance in a loose granular soil could encourage a redistribution of particles contact leading to rather denser overburden and a surface settlement depression that could be of somewhat greater volume than the ground lean volume at the tunnel. There have been many researches for tunneling in undrained clay which involves various approaches for the estimation of ground movements such as empirical methods
[2-4], analytical method [5, 6], physical modeling [7-9], and numerical methods $[10,11]$. Settlement trough shape generally matches well with a Gaussian curve [2], with the maximum settlement, $S_{\max }$, and the horizontal distance to the inflexion point, $i$, defining the shape of the curve. The value of $i$ has been found to vary with the vertical distance between the tunnel and the depth of interest [2, 3, 12]. Many researchers, however, have provided data suggesting that it is also a function of tunnel diameter, especially for low coverto-diameter ratios $[13,14]$.

For tunnels in sands, it has been observed that the Gaussian curve does not always provide a good fit to settlement trough data in drained soils $[8,15,16]$, which may also explain some of the scatters in the published $i$ values for tunnels in sands and gravels. In the analysis of real tunnel data, such as those provided by [17], it is difficult to establish the effect of individual parameters, since the variability of such factors as soil type, 
construction method, and measurement errors between tunneling projects inevitably affects the results. This may be the reason for limited research in granular soils compared to the clay soil.

The main purpose of the present study is to propose an influence zone around tunneling in sands in Greenfield condition. The general criterion described by [1] for buildings outside the $10 \mathrm{~mm}$ settlement contour or with a maximum distortion of less than $1 / 500$ no further action is required. This may be considered in instrumentation program during tunneling activities for monitoring displacements in recent days. Mostly, $10 \mathrm{~mm}, 15 \mathrm{~mm}$, and $20 \mathrm{~mm}$ settlements are taken as alert level, action level, and alarm level, respectively, from the building settlement marker. Hence $10 \mathrm{~mm}$ is taken as the threshold value and settlement contour corresponding to this value is obtained directly from numerical modeling software PLAXIS. The importance of the effects transmitted is function of several parameters as the type of the works, and the mechanical characteristics such as tunnel size and placing depth [18]. Hence the effects of tunnel size, depth, type of soil, and volume loss are studied as well in proposing the influence zone. The region outside the zone can be considered as low risk or zero influence due to tunneling activities.

\section{Method for Estimating Tunneling- Induced Settlement}

For the case of a single tunnel in free field or Greenfield condition, the development of the surface settlement trough above and subsurface settlement around the tunnel is estimated by various methods as follows.

2.1. Empirical Method. O'reilly and New suggested, from case history reviews, that the following relations apply for United Kingdom tunnels having adequate ground settlement records [3].

For cohesive soils,

$$
i=0.43\left(z_{0}-z\right)+1.1 \text { meters }(3 \leq z o \leq 34) .
$$

For granular soils,

$$
i=0.28\left(z_{0}-z\right)-0.1 \text { meters }(6 \leq z o \leq 10),
$$

where $i=$ distance from the tunnel center line to the inflexion of the trough, $m, z_{0}=$ depth of the axis of tunnel, and $m$, $z=$ depth from where settlement is to be found, $m$.

The Gaussian distribution for ground settlement proposed by [2] is used for predicting the ground settlement [4]. Observed the subsurface settlement due to a tunnel drive. The observed subsurface settlement and predicted subsurface settlement are compared and it is noticed that the subsurface settlement is overpredicted by Gaussian distribution curve with an empirical constant value of $k=0.5$. Mair et al. [4] modified the gauss distribution based on many site measurements and centrifuge test. The basic formula for ground settlement is

$$
\begin{aligned}
S & =S_{\max } \exp \left(\frac{-x^{2}}{2 i^{2}}\right), \\
S_{\max } & =\frac{V s}{\sqrt{ }(2 \pi i)}=1.252 \frac{V_{L} R^{2}}{i},
\end{aligned}
$$

where $x=$ lateral distance from tunnel centerline, $\mathrm{m}$, $\mathrm{S}_{\max }=$ maximum settlement, $\mathrm{mm}$, and $\mathrm{S}=$ ground settlement, $\mathrm{mm}, \mathrm{V}_{\mathrm{s}}=$ volume loss in $\%, \mathrm{~V}_{\mathrm{L}}=$ percentage of ground loss in $\%$, and $\mathrm{R}=$ radius of the tunnel, $\mathrm{m}$.

2.2. Analytical Method. Loganathan and Poulos proposed an analytical solution for the prediction of tunneling-induced undrained ground movements in clays [6]. Based on the gap parameter $g$ proposed by [19], a new parameter $\varepsilon$, named equivalent ground loss, is defined as follows:

$$
\varepsilon=\frac{4 R g+g^{2}}{4 R^{2}}
$$

Ground settlement is obtained by

$$
u_{0}=4(1-v) R^{2} \varepsilon \frac{H}{\left(x^{2}+H^{2}\right)} \exp \left[-\frac{1.38 x^{2}}{(H+R)^{2}}\right] \text {, }
$$

where $u_{0}=$ ground surface settlement, $\mathrm{mm}, R=$ tunnel radius, $\mathrm{m}, \mathrm{G}=$ gap parameter, $\mathrm{mm}, H=$ depth of tunnel horizontal axis level, $\mathrm{m}, V=$ Poisson's ratio, $\varepsilon=$ ground loss ratio (volume of the settlement trough over excavated volume per meter length), and $X=$ lateral distance from tunnel centerline, $\mathrm{m}$.

2.3. Numerical Analysis. Ground heterogeneity, soil nonlinearity, advanced soil models, $3 D$ effects, complex tunnel geometries, the interaction with surrounding structures, and the tunnel construction method and sequence are well accounted in numerical analysis, while empirical and analytical methods provide a simple and practical means of estimating tunneling-induced ground movements [20]. As mentioned by [21] often not all the actual field tunneling sequences can be fully replicated in a numerical analysis; some assumptions and simplification are thus required.

\section{Prediction of Settlement Induced by Tunneling}

3.1. Assumptions in Numerical Modelling. The assumptions and simplifications made in this study are as follows. (i) Soil fill is homogeneous and isotropic. The behaviour of the soil is assumed to obey the Mohr-Coulomb failure criterion and to follow the elastic-plastic stress-strain relationship. The mechanical behaviours of soils may be modeled at various degrees of accuracy. The linear elastic perfectly plastic Mohr-Coulomb (MC) model is often used to model soil behaviour in general [22]. (ii) The analysis is a full-face excavation analysis; thus the influence of staged excavation as commonly employed in New Austrian Tunneling Method (NATM) is not considered. (iii) The primary support of the tunnel is concrete lining, represented by the elastic plate 
elements in this study, whereas many support systems by shotcrete lining are required in the numerical analysis for the estimation of squeezing and rockburst potential in water conveyance tunnel [23]. (iv) The horizontal boundary is taken to be the maxima of five times the tunnel diameter or two times the depth of the tunnel center and the vertical boundary is extended from the ground surface to 2.5 times the tunnel diameter below the tunnel center. (v) To obtain the ground surface settlement purely due to tunnel excavation and the relationship between the ground loss parameter and the contraction parameter, surcharge due to buildings and vehicles loadings on the ground surface are not considered in the analysis. (vi) The ground surface settlement is contributed mainly by tunnel excavation and the effect of consolidation settlement is insignificant for drained condition in this study since the subsoil where the tunnels are passing through is mostly cohesionless soil [24] and hence not considered for the analysis.

\subsection{Modeling Procedure of Tunneling in Soil}

(i) The left half of the model cross section is created in $2 \mathrm{D}$ and extended in $z$ direction up to $25 \mathrm{~m}$. The horizontal boundary is taken to be the maxima of five times the tunnel diameter. The vertical boundary is extended from the ground surface to 2.5 times the tunnel diameter below the tunnel center [26]. The left half of the tunnel element is placed at required depth and length $8 \mathrm{~m}$ which is the average length of TBM machine as shown in Figure 1.

(ii) Boundary condition of model must be prescribed, i.e., force equal to zero and free displacement. Model parameters are assigned to the soil under homogeneous condition using all the three properties for parametrical study as per Table 1 and plate elements to TBM as per Table 2 before meshing.

(iii) Mesh is generated as shown in Figure 2 throughout the model and refined especially inside the tunnel cluster and along the tunnel line.

(iv) Initial conditions comprising water condition and effective stresses are generated.

(v) While performing the calculation, the procedures followed are activation of tunnel lining, excavation of soil inside the cluster, application of tunnel face pressure maintained by a fluid (bentonite) with a unit weight of $14.0 \mathrm{kN} / \mathrm{m}^{3}$, and tunnel contraction which involves a shortening of the tunnel shell and thus a reduction of the tunnel radius during the calculation for simulation of volume loss $V_{\mathrm{L}}$.

(vi) Tunnel excavation is simulated by removing the soil located in the excavation zone; i.e., soil is excavated inside the tunnel lining and surrounding the tunnel lining by deactivating the soil element. As for the cases that consider only volume loss without the effect of weight loss, soil is excavated surrounding the tunnel lining only [27]. The excavation of a tunnel leads to stress relief in the soil surrounding

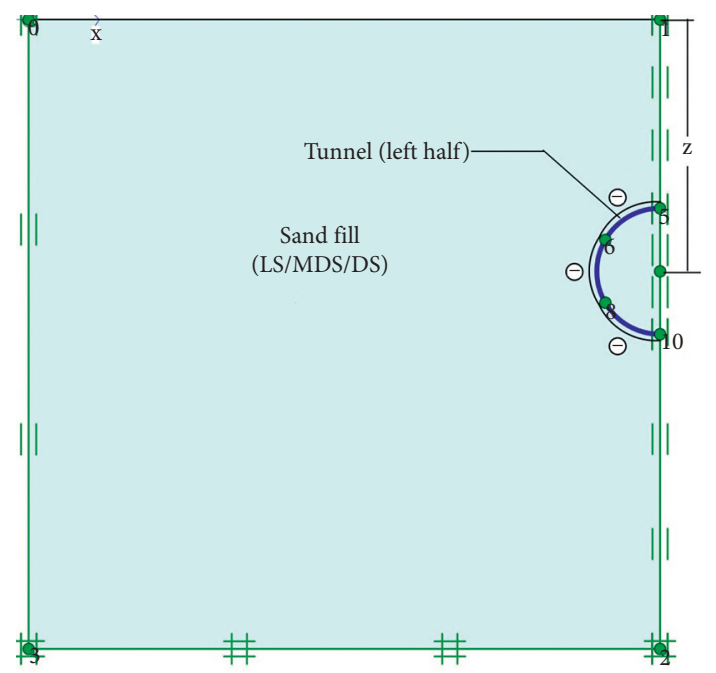

Figure 1: Model cross section. Model is created with fixities all around and filled inside with sands of different denseness under homogeneous condition. Left half of the tunnel is placed at depth " $z$."

the tunnel, and consequently, the soil mass moves towards the excavation. These ground movements induced by tunneling are often characterized by the term ground volume loss $V_{\mathrm{L}}$, which is the volume of material lost in the region of tunnel, occurring through subsurface construction process, and it is expressed as a percentage of theoretical excavated volume of the tunnel [28]. Volume loss $\left(V_{\mathrm{L}}\right)$ is often referred to as ground loss. (vii) Settlement characteristics are studied by analyzing the output consisting of deformed mesh as shown in Figure 3. Figure 4 shows the detailed analysis of the desired settlement contour where $10 \mathrm{~mm}$ is taken as the threshold value to plot the contour.

3.3. Validation of Numerical Analysis Results. To validate the results obtained from the numerical analysis, the measured maximum settlement along the tunnel centerline and surface settlement from empirical approach using equations (3) and (4) for sand or granular soils are compared. The details of tunnels in sands for which the comparison is made are given in Table 3. From Table 3, it is observed that there is a fair agreement in the analysis of surface settlement among numerical analysis, measured value reported in the literature studies, and empirical methods.

\subsection{Characteristic Study of Settlement Trough and Contour.} Base case parameters are assumed to study the characteristics of settlement trough and contour with varying tunnel sizes and placing depth, respectively. Since the loose sand shows significant effect on the settlement characteristics it is chosen for the study, assuming the properties given in Table 1. As far as the closed face tunneling using EPB or slurry shields particularly in cohesionless deposits the volume losses that are often as low as $0.5 \%[12,34]$, the upper 
TABLE 1: Material properties of sand layer [25].

\begin{tabular}{|c|c|c|c|c|}
\hline Parameter & Loose sand (LS) & Medium dense sand (MDS) & Dense sand (DS) & Unit \\
\hline Material model & Mohr-Coulomb & Mohr-Coulomb & Mohr-Coulomb & - \\
\hline Material behaviour & Drained & Drained & Drained & - \\
\hline Unsaturated unit weight, $\left(\gamma_{\text {unsat }}\right)$ & 16 & 17 & 18 & $\mathrm{kN} / \mathrm{m}^{3}$ \\
\hline Saturated unit weight, $\left(\gamma_{\text {sat }}\right)$ & 19 & 20 & 21 & $\mathrm{kN} / \mathrm{m}^{3}$ \\
\hline Young's modulus, $E$ & $1.5 \mathrm{E}+04$ & $3.0 \mathrm{E}+04$ & $4.5 \mathrm{E}+04$ & $\mathrm{kN} / \mathrm{m}^{2}$ \\
\hline Poisson's ratio, $v$ & 0.3 & 0.35 & 0.4 & - \\
\hline Cohesion (constant for sand) & 1 & 1 & 1 & $\mathrm{kN} / \mathrm{m}^{2}$ \\
\hline Friction angle, $\varphi$ & 30 & 35 & 40 & 0 \\
\hline Dilatancy angle, $\psi$ & 0 & 5 & 10 & 0 \\
\hline
\end{tabular}

TABLE 2: Material properties of TBM [29].

\begin{tabular}{lcc}
\hline Parameter & Value & Unit \\
\hline Material behaviour & Elastic & - \\
Nominal stiffness, EA & $8.2 \mathrm{E}+06$ & $\mathrm{kN} / \mathrm{m}$ \\
Flexural rigidity, EI & $8.38 \mathrm{E}+04$ & $\mathrm{kNm} / \mathrm{m}$ \\
Equivalent thickness, $d$ & 0.35 & $\mathrm{~m}$ \\
Weight & 38.5 & $\mathrm{kN} / \mathrm{m} / \mathrm{m}$ \\
\hline
\end{tabular}

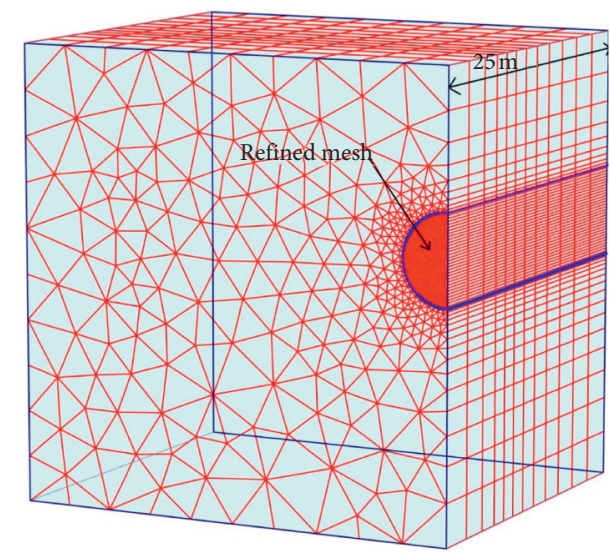

FIGURE 2: Mesh Generation. Coarse mesh is generated throughout the model and refined inside the tunnel.

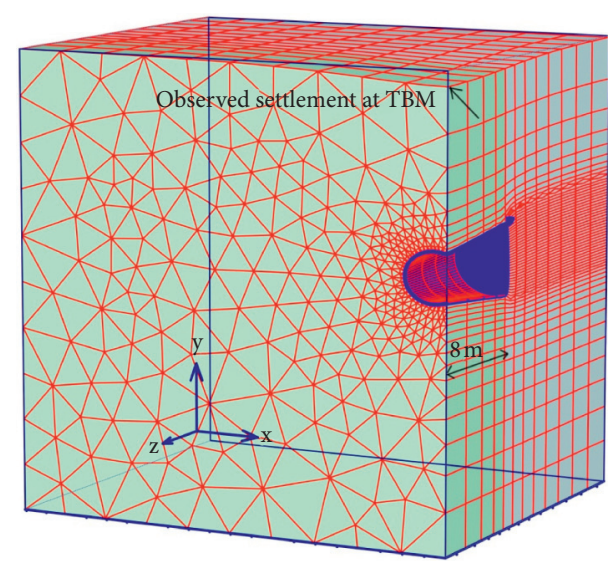

FIGURE 3: Deformed mesh after performing calculation. Settlement is observed at the surface due to volume loss for first $8 \mathrm{~m}$ (TBM length).

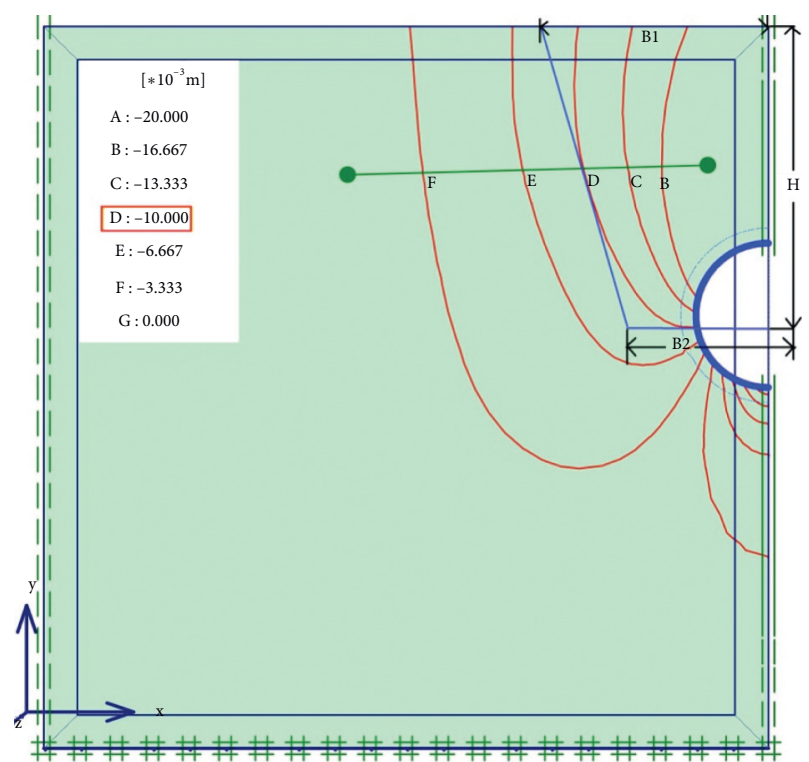

Figure 4: Settlement contour. From different contours $10 \mathrm{~mm}$ settlement contour " $D$ " is measured.

bound value of $0.5 \%$ was taken as constant volume loss throughout the settlement characteristic study.

3.4.1. Variation of Tunnel Sizes. Tunnel size around $3 \mathrm{~m}$ is considered to be small tunnel and it is often used as drainage scheme or sewerage system as illustrated in Table 3. Tunnel sizes of $6 \mathrm{~m}$ and $9 \mathrm{~m}$ are considered to be medium and large tunnel, respectively, that facilitate transport especially and other facilities like water conveyance. To study the characteristics of settlement trough in variation with the tunnel sizes, i.e., tunnel diameter, $D$ of $6 \mathrm{~m}$ are taken as base and analyses are carried out for $0.5 \mathrm{D}, 1 \mathrm{D}$, and $1.5 \mathrm{D}$ at constant placing depth, $\mathrm{H}$ equal to twice of the base diameter, i.e., 
TABle 3: Details of tunnels in sands and maximum surface settlement, $s_{\max }$.

\begin{tabular}{|c|c|c|c|c|c|c|c|c|c|c|c|}
\hline \multirow[b]{2}{*}{ No. } & \multirow[b]{2}{*}{ Source } & \multirow[b]{2}{*}{ Location } & \multirow{2}{*}{$\begin{array}{l}\text { Ground } \\
\text { conditions }\end{array}$} & \multirow{2}{*}{$\begin{array}{l}\text { Excavation } \\
\text { methods }\end{array}$} & \multirow{2}{*}{$\begin{array}{l}\text { Tunnel } \\
\text { diameter } \\
(\mathrm{m})\end{array}$} & \multirow{2}{*}{$\begin{array}{l}\text { Depth } \\
\text { to } \\
\text { tunnel } \\
\text { axis H, } \\
(\mathrm{m})\end{array}$} & \multirow{2}{*}{$\begin{array}{l}\text { Volume } \\
\text { loss } V_{\mathrm{L}} \\
(\%)\end{array}$} & \multirow{2}{*}{$\begin{array}{l}\text { Inflection } \\
\text { point, I } \\
\text { (m) }\end{array}$} & \multicolumn{3}{|c|}{$\begin{array}{l}\text { Maximum settlement along } \\
\text { tunnel center line, } S_{\max }(\mathrm{mm})\end{array}$} \\
\hline & & & & & & & & & Measured & PLAXIS & $\begin{array}{c}\text { Empirical } \\
\text { approach } \\
{[3]}\end{array}$ \\
\hline 1 & {$[30]$} & London, UK & $\begin{array}{l}\text { Medium to } \\
\text { coarse sand } \\
\text { with some } \\
\text { gravel }\end{array}$ & $\begin{array}{l}\text { Bentonite } \\
\text { shield }\end{array}$ & 4.1 & 10.1 & 0.9 & 5.0 & 22 & 18.5 & 17.3 \\
\hline 2 & {$[31]$} & $\begin{array}{l}\text { Washington, } \\
\text { USA section a }\end{array}$ & $\begin{array}{l}\text { Medium } \\
\text { dense silty } \\
\text { sand }\end{array}$ & $\begin{array}{c}\text { Shield } \\
\text { articulated } \\
\text { with digger } \\
\text { arm }\end{array}$ & 6.4 & 20.9 & 0.1 & 5.1 & 6 & 7 & 2.23 \\
\hline 3 & {$[32]$} & $\begin{array}{c}\text { Ayrshire, UK } \\
\text { Joint drainage } \\
\text { scheme }\end{array}$ & $\begin{array}{l}\text { Loose silty } \\
\text { sand with } \\
\text { little gravel }\end{array}$ & $\begin{array}{l}\text { Shield hand } \\
\text { excavated }\end{array}$ & 2.9 & 5.7 & 0.77 & 1.6 & 16 & 17.4 & 13.5 \\
\hline 4 & [33] & $\begin{array}{l}\text { Tokyo, Japan } \\
\text { site III } \\
\end{array}$ & $\begin{array}{c}\text { Fine silty } \\
\text { sand }\end{array}$ & Blind shield & 3.7 & 22.1 & 2.1 & 8.2 & 32 & 30.6 & 29.1 \\
\hline 5 & [31] & $\begin{array}{l}\text { Illinois, USA } \\
\text { Rockford, } \\
\text { Illinois }\end{array}$ & $\begin{array}{l}\text { Medium } \\
\text { dense sand } \\
\text { with some } \\
\text { gravels }\end{array}$ & $\begin{array}{l}\text { Mechanical } \\
\text { shield }\end{array}$ & 3.0 & 10.8 & 2.9 & 2.0 & 25 & 26.7 & 27.9 \\
\hline 6 & [3] & $\begin{array}{l}\text { Warrington, } \\
\text { UK }\end{array}$ & $\begin{array}{l}\text { Loose and } \\
\text { silty sand }\end{array}$ & $\begin{array}{l}\text { Shield, hand } \\
\text { excavated } \\
\text { compressed } \\
\text { air }\end{array}$ & 2.0 & 8.4 & 3.9 & 3.2 & 28 & 25.0 & 21.6 \\
\hline 7 & [14] & Taipei, Taiwan & Silty sand & EPBM & 6.1 & 18.5 & 1.0 & 7.4 & 26 & 23.9 & 22.9 \\
\hline
\end{tabular}

$12 \mathrm{~m}$. From Figure 5, it is observed that the magnitude of maximum surface settlement value is found to be increasing with increasing tunnel sizes. However, the inflection offset $i$, decreases with the increase in tunnel sizes.

3.4.2. Variation of Tunnel Placing Depth. Based on the general settlement criterion offered by [1], for buildings outside the $10 \mathrm{~mm}$ settlement contour no further action is required, $10 \mathrm{~mm}$ is taken as the threshold value, and settlement contour corresponding to this value is obtained for tunnels placed at different depths, i.e., $z=1 D$ (shallow tunneling), $2 D$ (intermediate tunneling), and $3 D$ (deep tunneling) as shown in Figure 6. Increasing placing depth and tunnel eccentricity, ground loss increases [35]. It is to be noted that the width of influence zone at both surface, $B_{1}$, and the end around tunnel outer skin $\mathrm{B}_{2}$ diminishes with the increasing depth of tunnel axis. With greater depth, the width $\mathrm{B}_{2}$ becomes zero, and hence the width $\mathrm{B}_{1}$ for even greater depths.

\section{Influence Zones from Parametrical Study}

The variation in tunnel sizes $D$ and placing depth of tunnel, $z$ greatly influence the characteristic behaviour of settlement contour as shown in Figures 5 and 6, respectively. Thus a parametrical study was carried out in the sands of different densities as given in Table 1, broadly classified as loose sand, medium dense sand, and dense sand. Underground tunnel parameters such as tunnel size " $D$ ” ( $3 \mathrm{~m}, 6 \mathrm{~m}$, and $9 \mathrm{~m})$, tunnel axis depth " $z$ " $(1 D, 2 D$, and $3 D)$, and volume loss " $V_{L}$ "

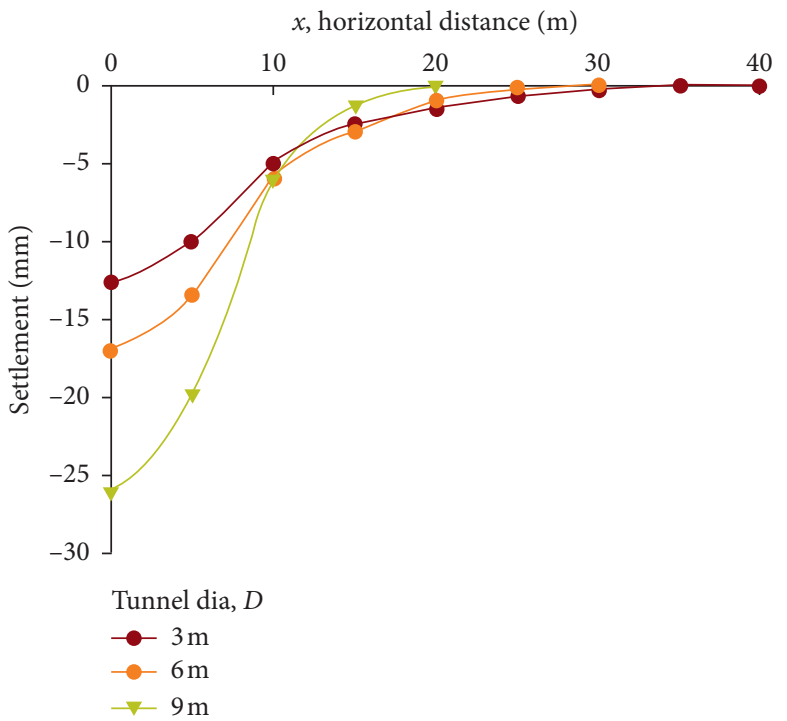

FIGURE 5: Settlement trough for different tunnel sizes. Surface settlement characteristics from tunnel centerline to outwards for 3 different tunnel diameters " $D$. "

with volume loss $0.5 \%$ as the base value $1 V_{\mathrm{L}}, 2 V_{\mathrm{L}}, 5 V_{\mathrm{L}}$, and $10 V_{\mathrm{L}}$, that is, $0.5 \%, 1.0 \%, 2.5 \%$, and $5.0 \%$, respectively, are being used in this study. The material properties of TBM given in Table 2 are used throughout the study.

The influence zones are arrived at from the $10 \mathrm{~mm}$ settlement contour by drawing a tangent normal to the 


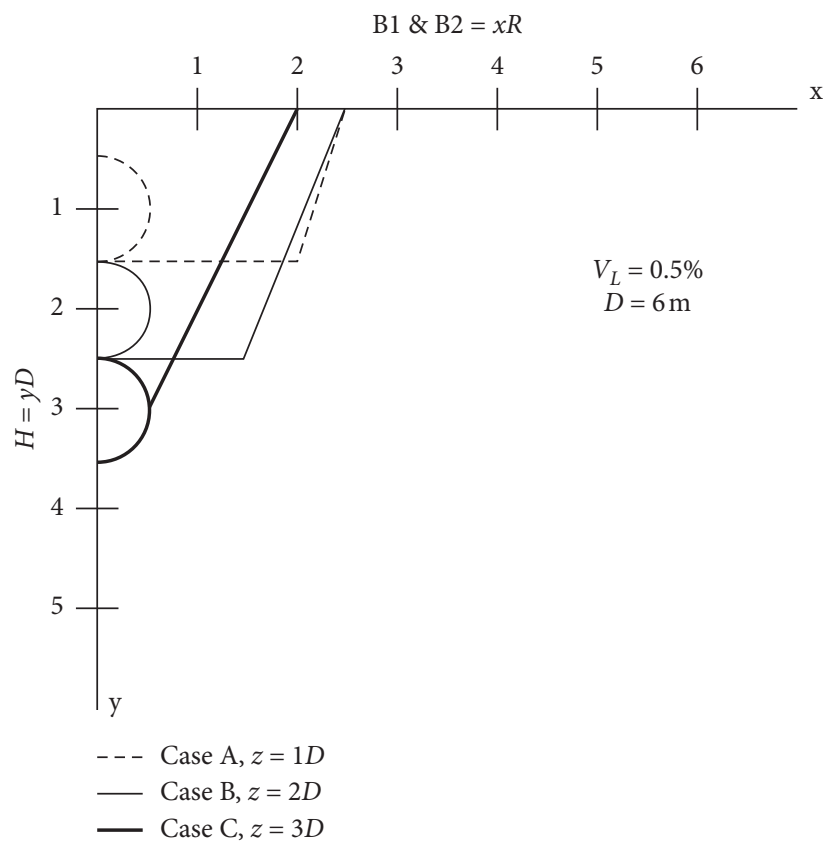

Figure 6: $10 \mathrm{~mm}$ settlement contour for different tunnel depths. Three cases A, B, and C for placing depths of tunnel at its sizes or diameter "D."

$\mathrm{B} 1 \& \mathrm{~B} 2=x R$

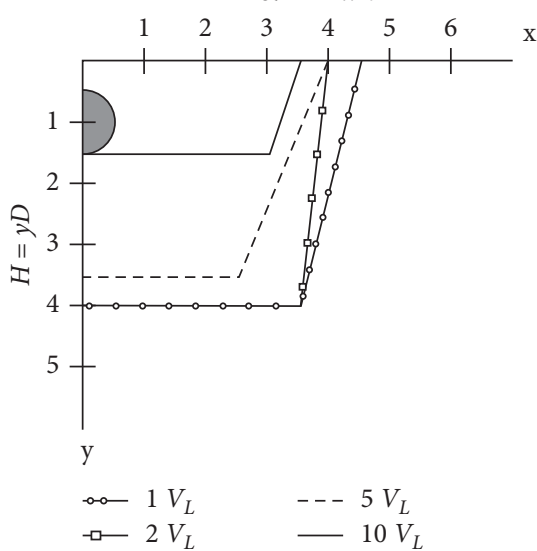

(a)

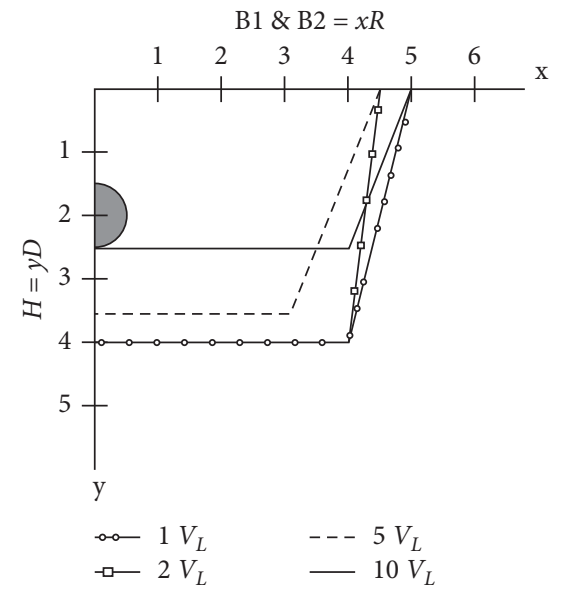

(d)

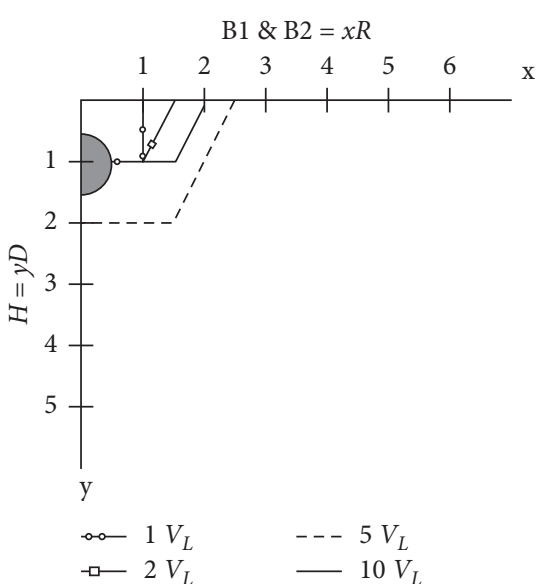

(b)

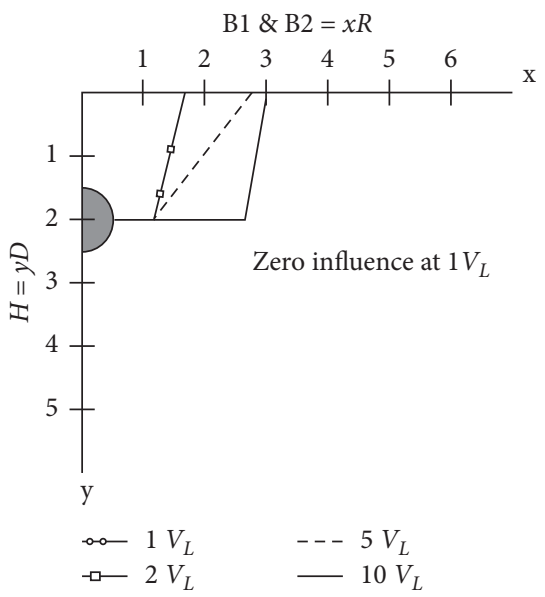

(e)

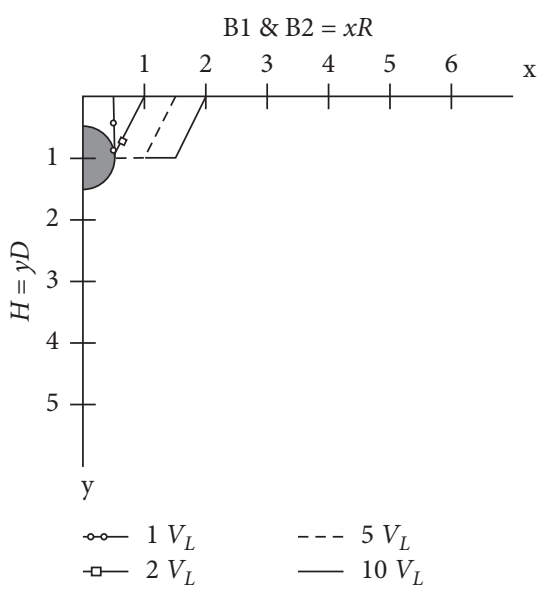

(c)

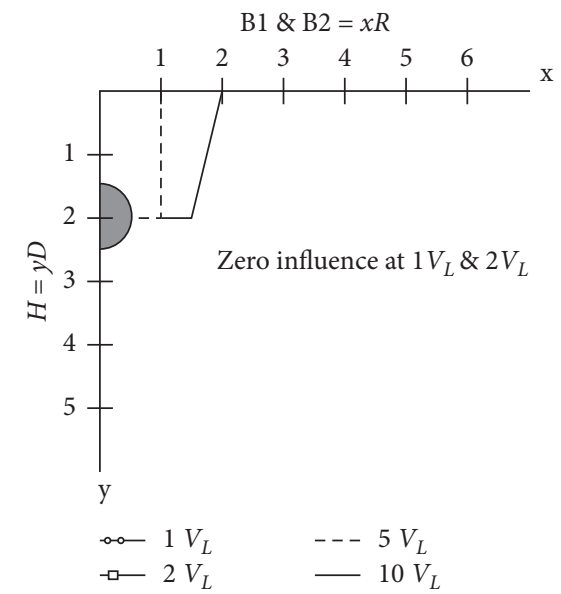

(f)

Figure 7: Continued. 


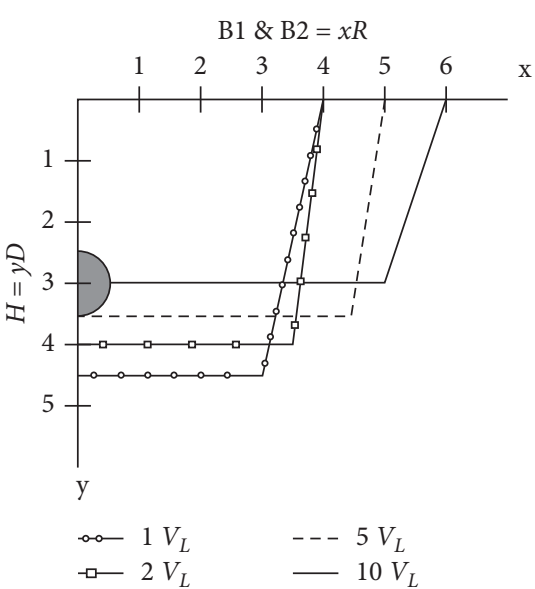

(g)

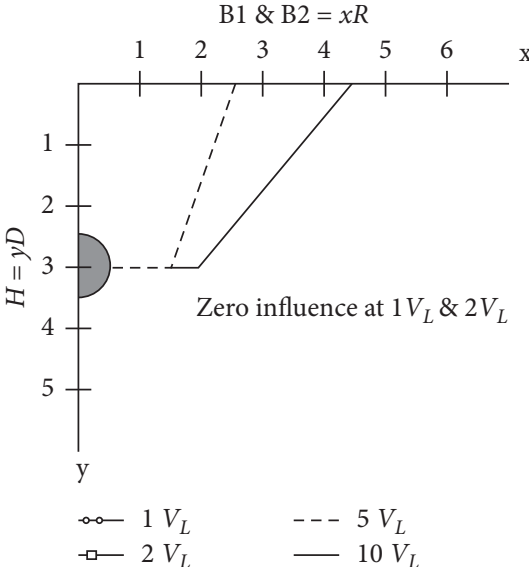

(h)

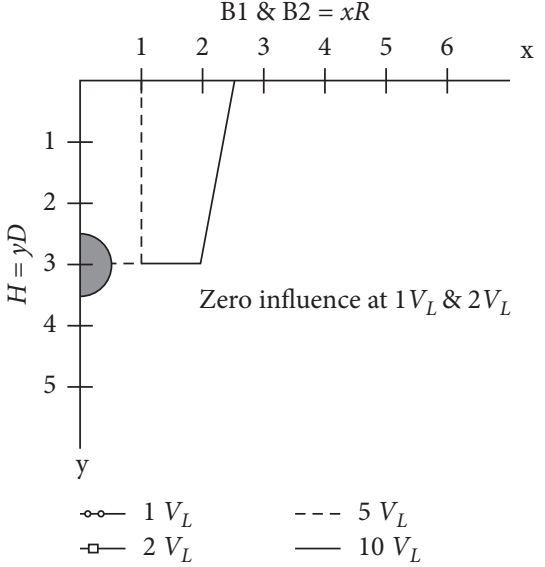

(i)

Figure 7: Influence zones for tunnel size, $D=3 \mathrm{~m}$. (a)-(c) Tunnel placed at depth of tunnel size " $D$ " for various volume loss percentage " $V_{L}$." (d)-(f) Tunnel placed at twice the depth of tunnel size " $D$." (g)-(i) Tunnel placed at thrice the depth of tunnel size " $D$." (a) $D=3 \mathrm{~m}$ and $z=1 D$ in LS. (b) $D=3 \mathrm{~m}$ and $z=1 D$ in MDS. (c) $D=3 \mathrm{~m}$ and $z=1 D$ in DS. (d) $D=3 \mathrm{~m}$ and $z=2 D$ in LS .(e) $D=3 \mathrm{~m}$ and $z=2 D$ in MDS .(f) $D=3 \mathrm{~m}$ and $z=2 D$ in DS .(g) $D=3 \mathrm{~m}$ and $z=3 D$ in LS. (h) $D=3 \mathrm{~m}$ and $z=3 D$ in MDS. (i) $D=3 \mathrm{~m}$ and $z=3 D$ in DS.

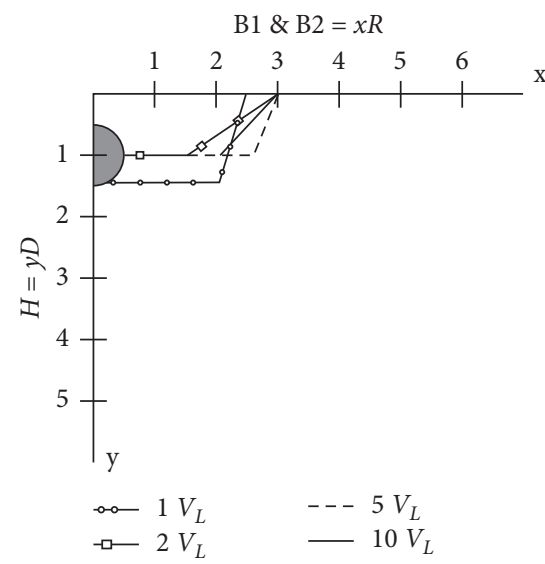

(a)

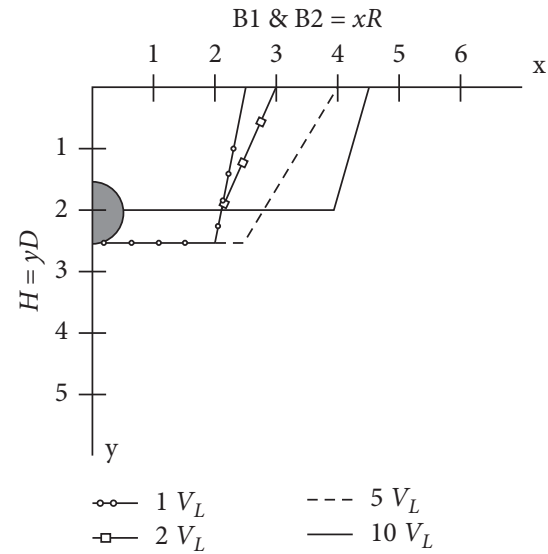

(d)

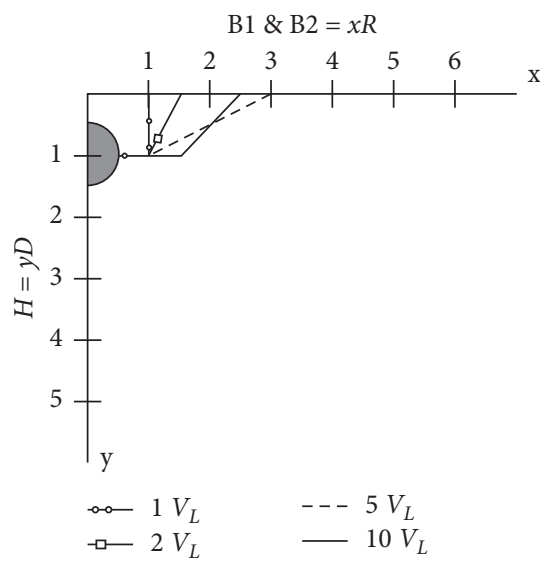

(b)

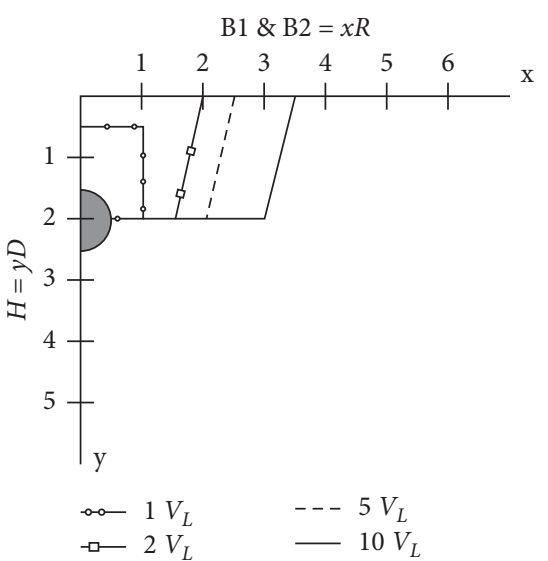

(e)

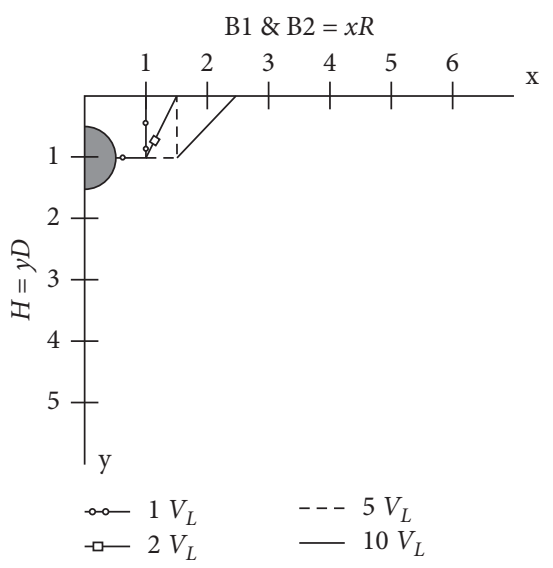

(c)

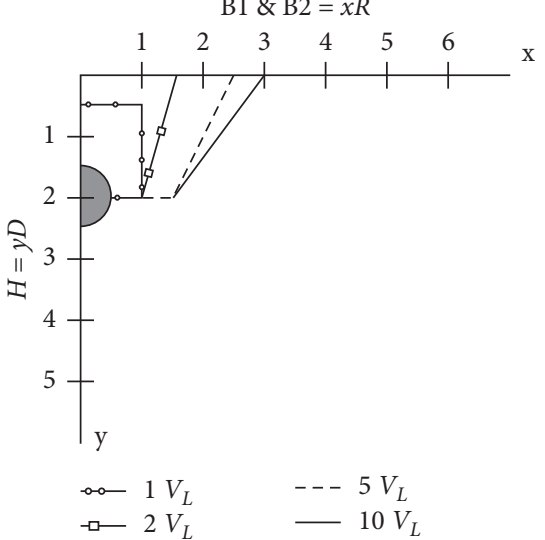

(f)

Figure 8: Continued. 


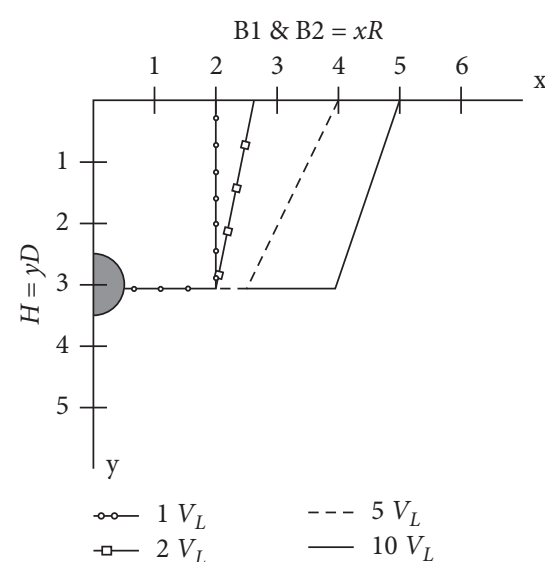

(g)

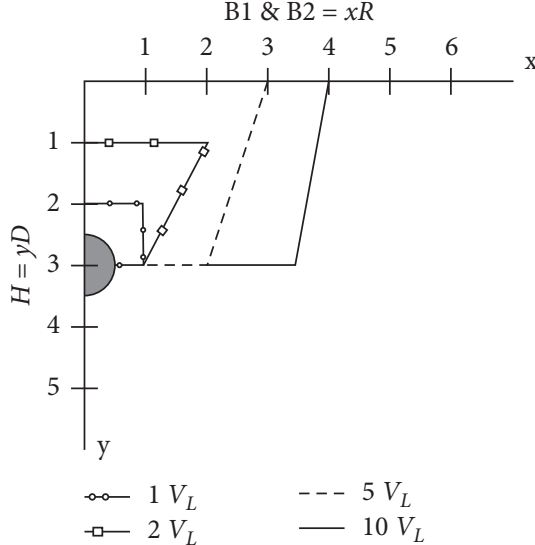

(h)

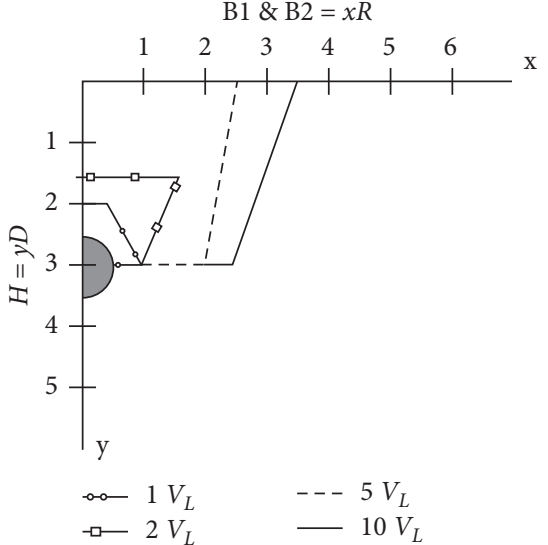

(i)

Figure 8: Influence zones for tunnel size, $D=6 \mathrm{~m} .8$ (a)-(c) Tunnel placed at depth of tunnel size " $D$ " for various volume loss percentage " $V_{L}$. " 8 (d)-(f) Tunnel placed at twice the depth of tunnel size " $D$." 8 (g)-(i) tunnel placed at thrice the depth of tunnel size " $D$." (a) $D=6 \mathrm{~m}$ and $z=1 D$ in LS. (b) $D=6 \mathrm{~m}$ and $z=1 D$ in MDS. (c) $D=6 \mathrm{~m}$ and $z=1 D$ in DS. (d) $D=6 \mathrm{~m}$ and $z=2 D$ in LS. (e) $D=6 \mathrm{~m}$ and $z=2 D$ in MDS. (f) $D=6 \mathrm{~m}$ and $z=2 D$ in DS. (g) $D=6 \mathrm{~m}$ and $z=3 D$ in LS. (h) $D=6 \mathrm{~m}$ and $z=3 D$ in MDS. (i) $D=6 \mathrm{~m}$ and $z=3 D$ in DS.

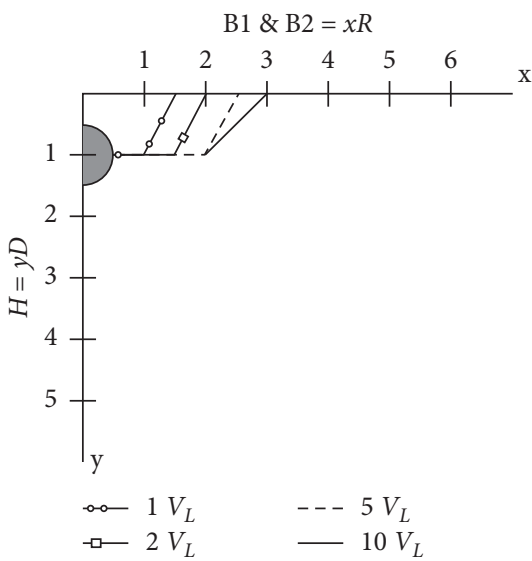

(a)

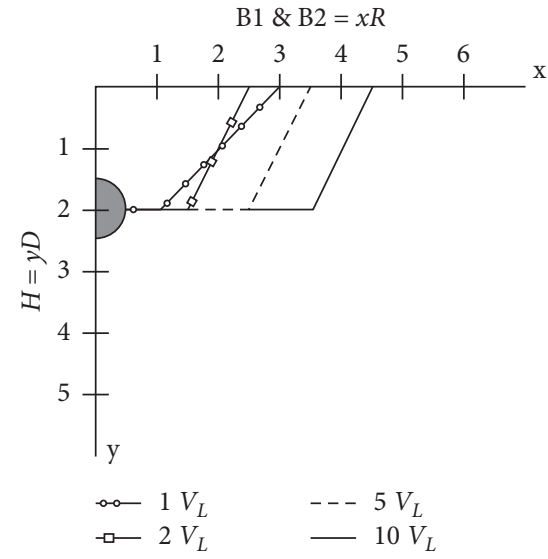

(d)

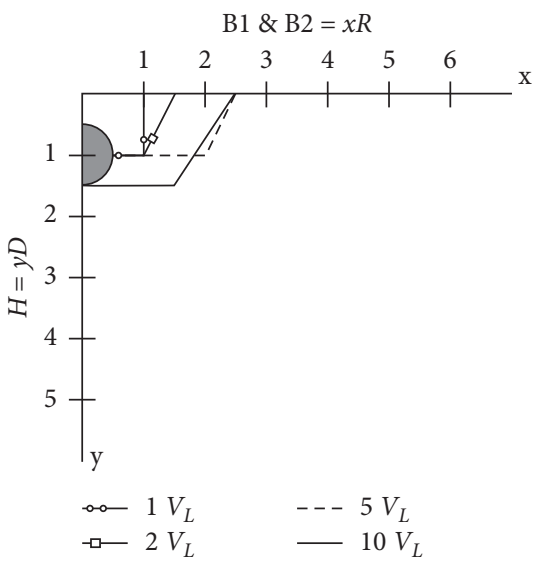

(b)

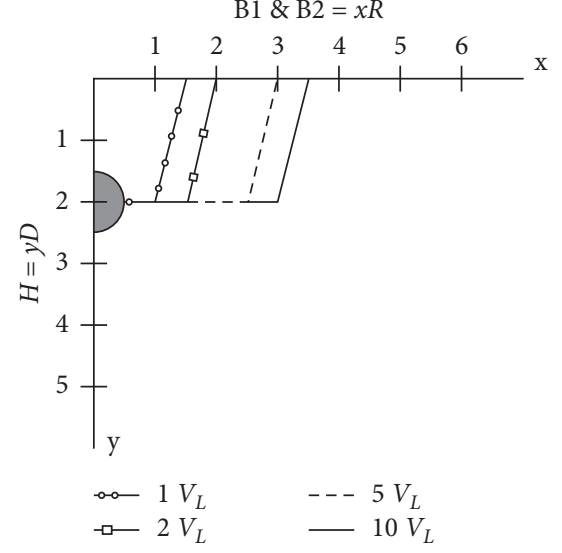

(e)

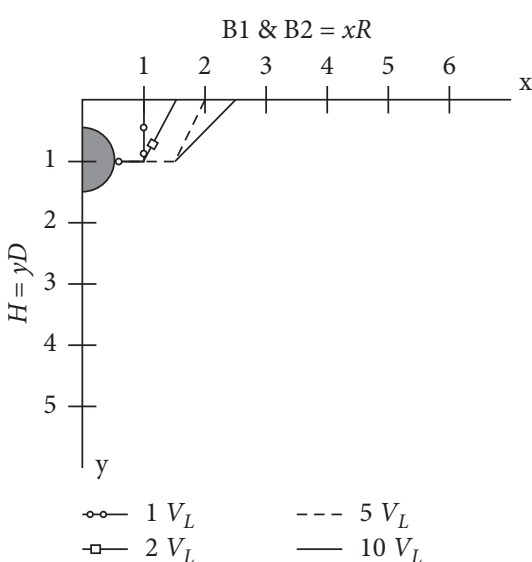

(c)

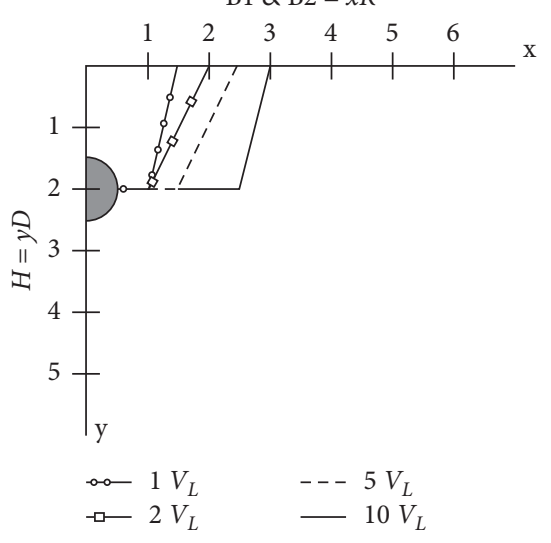

(f)

FIgUre 9: Continued. 


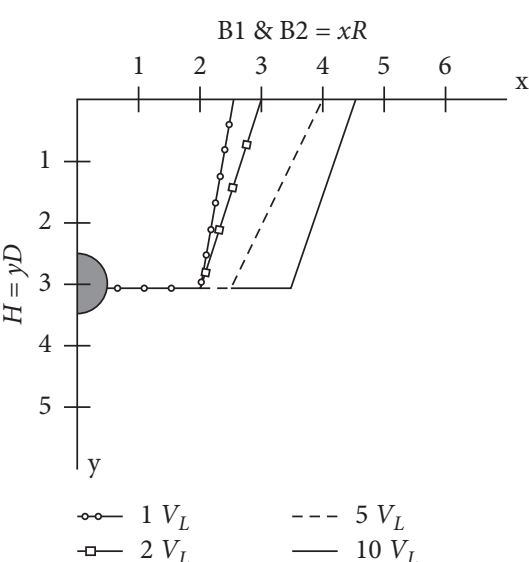

$(\mathrm{g})$

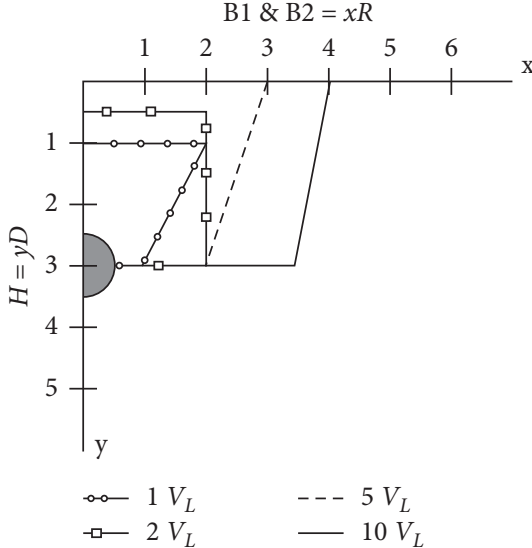

(h)

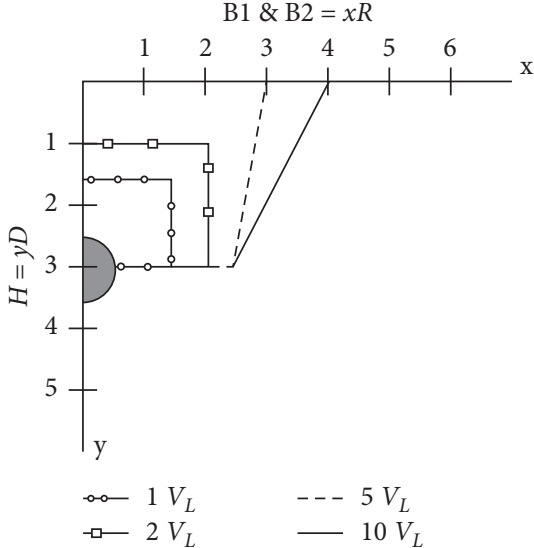

(i)

Figure 9: Influence zones for tunnel size, $D=9 \mathrm{~m}$. (a)-(c) Tunnel placed at depth of tunnel size " $D$ " for various volume loss percentage " $V_{L}$." (d)-(f) Tunnel placed at twice the depth of tunnel size " $D$." (g)-(i) tunnel placed at thrice the depth of tunnel size " $D$." (a) $D=9 \mathrm{~m}$ and $z=1 D$ in LS. (b) $D=9 \mathrm{~m}$ and $z=1 D$ in MDS. (c) $D=9 \mathrm{~m}$ and $z=1 D$ in DS. (d) $D=9 \mathrm{~m}$ and $z=2 D$ in LS. (e) $D=9 \mathrm{~m}$ and $z=2 D$ in MDS. (f) $D=9 \mathrm{~m}$ and $z=2 D$ in DS. (g) $D=9 \mathrm{~m}$ and $z=3 D$ in LS. (h) $D=9 \mathrm{~m}$ and $z=3 D$ in MDS. (i) $D=9 \mathrm{~m}$ and $z=3 D$ in DS.

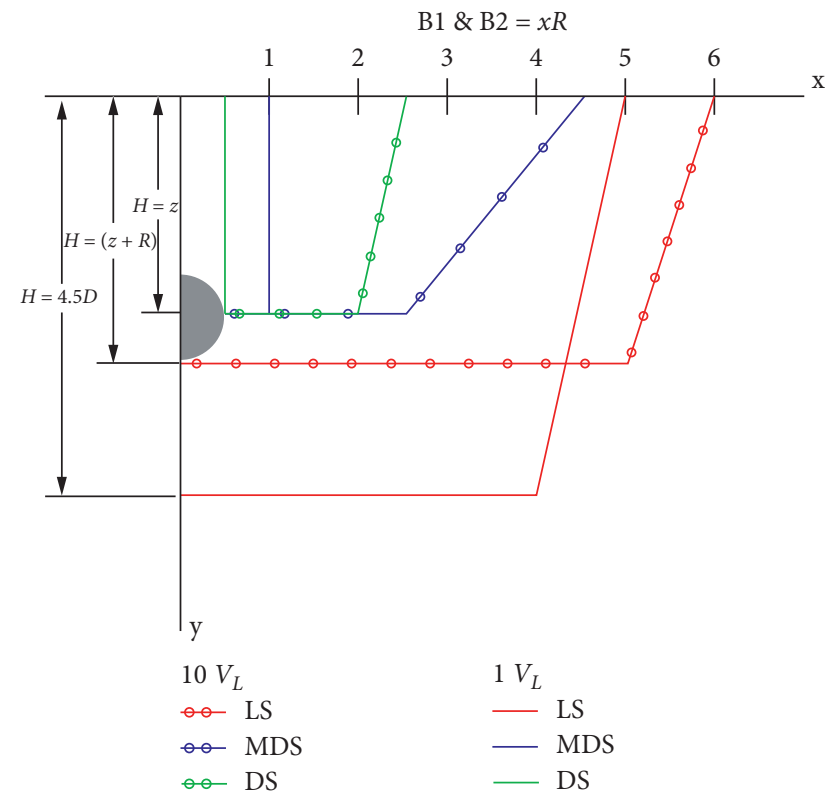

Figure 10: Influence zones for small tunnel $(D=3 \mathrm{~m})$. B1 and B2 are top and bottom width of influence zone measured in terms of tunnel radius " $R$." " $H$ " is height of influence zones in terms of tunnel diameter " $D$."

maximum point of curvature as shown in Figure 4 which makes widths $B_{1}$ and $B_{2}$ at the surface from the tunnel centerline to the end of contour line and at the bottom around tunnel periphery, respectively. $\mathrm{B}_{2}$ is found most probably at placing depth, $z$, or sometimes beyond the placing depth based on the soil condition and its associated volume losses due to tunneling activities. The height $H$ is the depth of influencing zone which starts from $B_{1}$ to $B_{2}$ along the tunnel centerline. These widths and heights are the multiples $(x$ and $y$ ) of radius, $R$, and diameter, $D$, of the

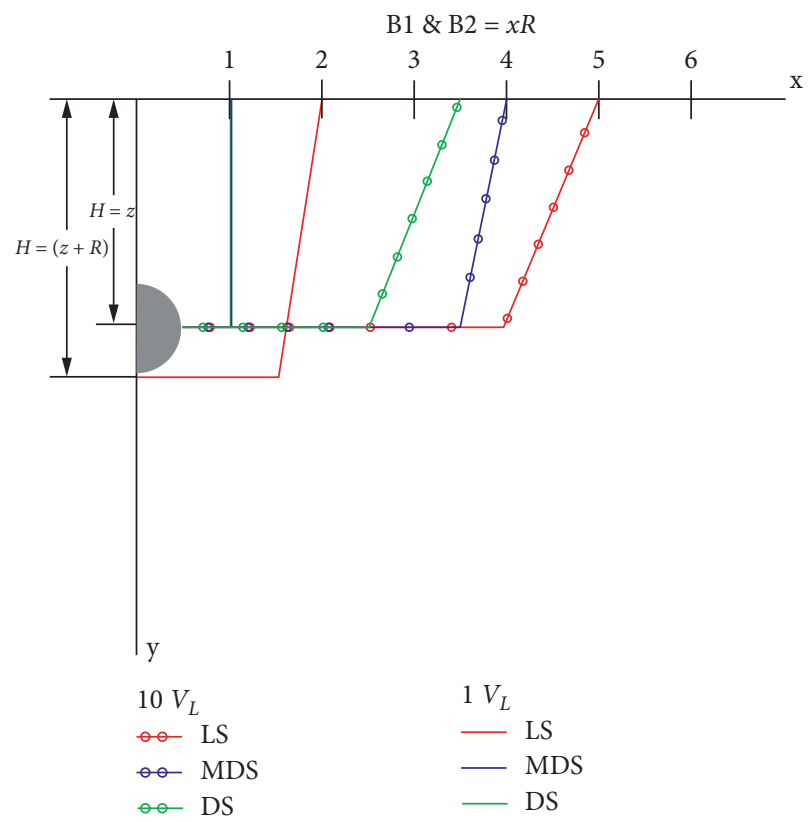

Figure 11: Influence zones for medium tunnel $(D=6 \mathrm{~m}) . \mathrm{B} 1$ and B2 are top and bottom width of influence zone measured in terms of tunnel radius " $R$." " $H$ " is height of influence zones in terms of tunnel diameter " $D$."

tunnel, respectively. Influencing zones are plotted in the shape of trapezoid which is considered to be overestimated and gives the scope for conservative approach in tunnel design and alignment.

\section{Analyses of Results}

The influence lines generated from the validated finite element method (FEM) numerical analysis for various 27 cases involving different soil and tunnel parameters shown in 


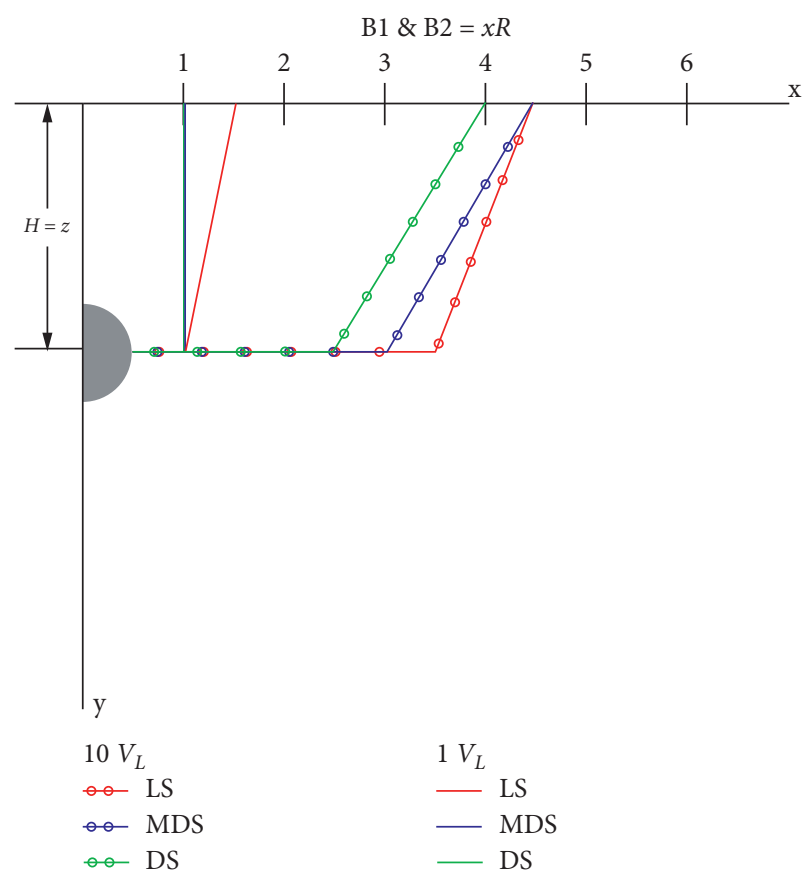

FIGURE 12: Influence zones for large tunnel $(D=9 \mathrm{~m})$. B1 and B2 are top and bottom width of influence zone measured in terms of tunnel radius " $R$. ." " $H$ " is the height of influence zones in terms of tunnel diameter " $D$."

Figures 7-9 are combined together and represented in Figures 10-12 for three different tunnel sizes, $D=3 \mathrm{~m}, 6 \mathrm{~m}$, and $9 \mathrm{~m}$, respectively. Likewise the different sand denseness conditions given in Table 1 are incorporated in combining the influence zones. The soil parameters influence in the surface settlement due to tunneling is evident from [36]. Increase in cohesion and elastic modulus shows the reduced surface settlement as the strength of the ground is increased. In controversy to cohesive soil the increase in friction angle, dilatancy angle, and Poisson's ratio has increased the surface settlement in cohesionless deposits. The volume losses $0.5 \%\left(1 V_{L}\right)$ and $5.0 \%\left(10 V_{L}\right)$ are considered to be the lower bound and upper bound values, respectively, for plotting the influence zones.

Unlike other tunnel sizes, the smaller diameter tunnel $(D=3 \mathrm{~m})$ in the loose sand shows maximum magnitude of influencing zone below the placing depth to $4.5 \mathrm{D}$ for smaller volume loss (say $0.5 \%$ ) as shown in Figure 10. The stress redistribution from overburden soil must be the reason for the possibility of influencing zone below the tunnel especially of smaller diameter. This effect reduces when the tunnel diameter increases. The self-weight of the tunnel and grains redistribution may increase the settlement in loose sand below the bottom of the tunnel. The behaviour of influencing width B1 in small tunnel is typical to other tunnel dimensions and volume loss. As the denseness of sand increases the width and the height of influencing zone reduce as tunneling disturbance in a loose granular soil could encourage a more redistribution of particle contact rather than in dense soil. For greater tunnel sizes, $D=6 \mathrm{~m}$ and $9 \mathrm{~m}$, with higher volume loss, the influencing zone and similar response are observed for these two tunnel sizes like small tunnels with respect to soil denseness, as the dimensions of influencing zone reduce with increased densities of sand. However the height " $H$ " of the influencing zone along the tunnel centerline is equal to the placing depth " $z$ " of the tunnel for greater tunnel sizes and higher densities of sand. If a tunnel is to be located within these influence zones, detailed assessment and volume loss control with a complete instrumentation program are essential during the design and erection stages, respectively.

\section{Conclusions}

FEM with reasonable soil models and assumptions is adopted to meet the challenges faced in the instrumentation program. It is often used to model complex soil-structure interactions [37]. Three-dimensional finite element analyses are engaged to study the settlement responses due to the tunneling of different sizes in different soils and the influences of various parameters on them. The results of numerical analysis indicate that different soil and tunnel parameters can be considered for shallow, intermediate, and deep tunneling conditions. A series of parametric studies are carried out to generate the artificial data for plotting the influence zones in which the following parameters are varied: the tunnel diameter $(D)$ and the volume loss $\left(V_{L}\right)$, placing depth of tunnel $(z)$ and different denseness of sands. By these numerically generated data together with the above said criteria, the zones of influence are arrived as shown in Figure 10-Figure 12. Based on the tunnel geometry and evaluated volume loss in sands under green field condition, vulnerable zone may be predicted in the field before execution by utilizing the influence zones arrived in this study. This helps the engineers to take precautionary actions before and during tunneling activities to avoid any accidents. The responses of building foundation within these zones are the scope of interest for future research.

\section{Data Availability}

The data used to support the findings of this study are included within the article.

\section{Conflicts of Interest}

The authors declare that they have no conflicts of interest.

\section{Acknowledgments}

The 3-dimensional finite element program PLAXIS 3D Tunnel used in the current research has been rendered by Dr. K. Rajagopal, Professor in Civil Engineering, Indian Institute of Technology Madras, Chennai, India, who has been a constant source of guidance and valuable suggestions throughout the study.

\section{References}

[1] P. B. Attewell, J. Yeates, and R. Alan Selby, Soil Movements Induced by Tunnelling and Their Effects on Pipelines and Structures, Blackie, London, UK, 1986. 
[2] R. B. Peck, "Deep excavations and tunneling in soft ground," in Proceedings of 7th ICSMFE, Mexico Geotechnical Society, Mexico city, Mexico, pp. 225-290, 1969.

[3] M. P. O'reilly and B. M. New, "Settlements above Tunnels in the United Kingdom-their Magnitude and Prediction," in Proceedings of the Tunnelling, Institution of Mining and Metallurgy, pp. 173-181, London, UK, 1982.

[4] R. J. Mair, R. N. Taylor, and A. Bracegirdle, "Subsurface settlement profiles above tunnels in clays," Géotechnique, vol. 43, no. 2, pp. 315-320, 1993.

[5] A. Verruijt and J. R. Booker, "Surface settlements due to deformation of a tunnel in an elastic half plane," Géotechnique, vol. 48, no. 5, pp. 709-713, 1998.

[6] N. Loganathan and H. G. Poulos, "Analytical prediction for tunneling-induced ground movements in clays," Journal of Geotechnical and Geoenvironmental Engineering, vol. 124, no. 9, pp. 846-856, 1998.

[7] W. H. Hansmire and E. J. Cording, "Performance of a soft ground tunnel on the Washington Metro," in Proceedings of the N Am Rapid Excav and Tunneling Conference, vol. 1, pp. 371-389, Chicaco, IL, USA, June 1972.

[8] S. W. Jacobsz, J. R. Standing, R. J. Mair, T. Hagiwara, and T. Sugiyama, "Centrifuge modelling of tunnelling near driven piles," Soils and Foundations, vol. 44, no. 1, pp. 49-56, 2004.

[9] A. M. Marshall, I. Elkayam, and A. Klar, "Ground behaviour above tunnels in sand-DEM simulations versus centrifuge test results," in Proceedings of the 2nd International Conference on Computational Methods in Tunnelling, Aedificatio Verlag, Bochum, Germany, pp. 9-11, September 2009.

[10] P. A. Vermeer, K. J. Bakker, and P. G. B. Plaxis, Finite Element Code for Soil and Rock Plasticity, Version 4: General Information and Tutorial Manual, Balkema, Avereest, The Netherlands, 1991.

[11] H. Mroueh and I. Shahrour, "Three-dimensional finite element analysis of the interaction between tunneling and pile foundations," International Journal for Numerical and Analytical Methods in Geomechanics, vol. 26, no. 3, pp. 217-230, 2002.

[12] R. J. Mair and R. N. Taylor, "Theme lecture: bored tunnelling in the urban environment," in Proceedings of the Fourteenth International Conference on Soil Mechanics and Foundation Engineering, Balkema, Rotterdam, The Netherland, pp. 2353-2385, September 1997.

[13] G. W. Clough and B. Schmidt, "Design and performance of excavations and tunnels in soft clay," Developments in Geotechnical Engineering, pp. 567-634, 1981.

[14] Z. C. Moh, D. H. Ju, and R. N. Hwang, "Ground movements around tunnels in soft ground," in Proceedings International Symposium on Geotechnical Aspects of Underground Construction in Soft Ground, vol. 730, Balkema, Tokyo, Japan, pp. 725-730, July 1996.

[15] T. B. Celestino, R. A. M. P. Gomes, and A. A. Bortolucci, "Errors in ground distortions due to settlement trough adjustment," Tunnelling and Underground Space Technology, vol. 15, no. 1, pp. 97-100, 2000.

[16] T. E. Vorster, A. Klar, K. Soga, and R. J. Mair, "Estimating the effects of tunneling on existing pipelines," Journal of Geotechnical and Geoenvironmental Engineering, vol. 131, no. 11, pp. 1399-1410, 2005.

[17] L. M. Lake, W. J. Rankin, and J. Hawley, Prediction and Effects of Ground Movements Caused by Tunnelling in Soft Ground beneath Urban Areas, CIRIA, London, UK, 1996.

[18] B. Nawel and M. Salah, "Numerical modeling of two parallel tunnels interaction using three-dimensional finite elements method," Geomechanics and Engineering, vol. 9, no. 6, pp. 775-791, 2015.
[19] K. M. Lee, R. K. Rowe, and K. Y. Lo, "Subsidence owing to tunnelling. I. Estimating the gap parameter," Canadian Geotechnical Journal, vol. 29, no. 6, pp. 929-940, 1992.

[20] F. Basile, "Effects of tunnelling on pile foundations," Soils and Foundations, vol. 54, no. 3, pp. 280-295, 2014.

[21] R. N. Taylor, "Modelling of tunnel behaviour," Proceedings of the Institution of Civil Engineers - Geotechnical Engineering, vol. 131, no. 3, pp. 127-132, 1998.

[22] S.-L. Chen, S.-C. Lee, and Y.-S. Wei, "Numerical analysis of ground surface settlement induced by double-o tube shield tunneling," Journal of Performance of Constructed Facilities, vol. 30, no. 5, Article ID 04016012, 2016.

[23] R. Bagherpour and M. J. Rahimdel, "The dangerous condition of ground during high overburden tunneling (a case study in Iran)," Periodica Polytechnica Civil Engineering, vol. 60, no. 1, pp. 11-20, 2016.

[24] C.-Y. Ou, R. N. Hwang, and W.-J. Lai, "Surface settlement during shield tunnelling at CH218 in Taipei," Canadian Geotechnical Journal, vol. 35, no. 1, pp. 159-168, 1998.

[25] M. R. Lindeburg, Civil Engineering Reference Manual for the PE Exam, Professional Publications, Hyderabad, India, 2001.

[26] S.-L. Chen, M.-W. Gui, and M.-C. Yang, "Applicability of the principle of superposition in estimating ground surface settlement of twin- and quadruple-tube tunnels," Tunnelling and Underground Space Technology, vol. 28, pp. 135-149, 2012.

[27] Y. Zang, P. Gan, J.-jia. Yan, S. Liu, and Z. Yan, "Effects of construction sequences and volume loss on perpendicularly crossing tunnels," Advances in Civil Engineering, 2019.

[28] J. Fu, J. Yang, K. Herbert, and S. Wang, "Analytical prediction of ground movements due to a nonuniform deforming tunnel," International Journal of Geomechanics, vol. 16, no. 4, Article ID 04015089, 2015.

[29] R. Brinkgreve, J. Bastiaan, and W. Broere, Plaxis: 3D TunnelVersion 2, AA Balkema, Avereest, The Netherlands, 2004.

[30] J. B. Boden and C. McCaul, "Measurement of ground movements during a bentonite tunnelling experiment," No. TRRL LR, vol. 653, 1974.

[31] H. H. MacPherson, Settlements around tunnels in soil: three case histories, Technical Report No. UMTA-IL-06-0043-78-1, United States Department of Transportation, Urban Mass Transportation Administration, Washington, DC, USA, 1978.

[32] H. S. Eadie and H. S. Eadie, Settlements observed above a tunnel in Sand. Tunnels and Tunnelling, vol. 5, no. 9, pp. 93-94, 1977.

[33] W. Yoshikoshi, O. Watanabe, and N. Takagi, "Prediction of ground settlements associated with shield tunnelling," Soils and Foundations, vol. 18, no. 4, pp. 47-59, 1978.

[34] M. Melis, M. Arnaiz, C. S. Oteo, and F. Mendana, "Ground displacements in Madrid soils due to tunnel excavation with earth pressure TBM," in Proceedings of the 14th Conference on Soil Mechanics and Foundation Engineering, pp. 1433-1436, Hamburg, Germany, September 1997.

[35] S. Hariswaran, K. Premalatha, and K. Raja, "Performance of strip footing on sandy soil due to tunneling," International Journal of Advanced Engineering and Technology, vol. 7, pp. 516-520, 2016.

[36] J. Liu and H. Zhang, "Semianalytical solution and parameters sensitivity analysis of shallow shield tunneling-induced ground settlement," Advances in Materials Science and Engineering, 2017.

[37] P. Jongpradist, T. Kaewsri, A. Sawatparnich et al., "Development of tunneling influence zones for adjacent pile foundations by numerical analyses," Tunnelling and Underground Space Technology, vol. 34, pp. 96-109, 2013. 